\title{
KONSEP DERADIKALISASI DAN KONTRA TERORISME MENURUT SAID NURSI
}

\author{
Muhammad Faiz \\ Institut Islam Hadhari, Universiti Kebangsaan Malaysia (UKM) \\ E-mail:gen_cang@yahoo.com
}

\begin{abstract}
Abstrak
Aksi positif (al-'amal al-ijabi) merupakan kaidah dasar yang menjadi asas pemikiran Said Nursi (1877-1960 M) dalam mewujudkan rasa aman dan kedamaian umat manusia secara umum maupun kebahagiaan duniawi dan ukhrawi umat Islam secara khusus. Amalan positif yang paling utama menurut Nursi adalah mengokohkan keimanan agar tercapai ridha Allah s.w.t., sebab khidmat keimanan menurutnya merupakan simbol teragung dan puncak dari semua aktifitas positif umat manusia. Oleh itu kajian ini akan mengungkap konsep Said Nursi dalam upaya deradikalisasi dan kontra terorisme yang masih menjadi masalah kemanusiaan sehingga kini. Kajian ini menggunakan metode kualitatif dalam menganalisis pemikiran dan gagasan Said Nursi mengenai konsep positifnya serta menghindari tindakan destruktif berdasarkan kajian kepustakaan terhadap karyanya Risale-i Nur. Di antara hasil penting dari kajian ini adalah bahwa asas pemikiran Said Nursi didasarkan atas nilai-nilai al-Quran dan al-Hadits yang membawa pesan perdamaian dan senantiasa menghindari tindakan negatif. Menurut Nursi, pembenahan bidang pendidikan, penguatan nilai-nilai positif dalam kehidupan sosial dengan mengedepankan cinta dan kasih sayang antar sesama serta gagasan jihad maknawi (al-jihad al-ma'nawi) merupakan solusi nyata untuk menyelamatkan kemanusiaan dari radikalisme dan terorisme.
\end{abstract}

Kata Kunci: Aksi Positif, Deradikalisasi, Kontra-terorisme, dan Jihad Maknawi.

\begin{abstract}
Positive action (al-'amal al-ijabi) is a basic rule which became the principle thought of Said Nursi (1877-1960) in creating a sense of security and peace of mankind in general and happiness especially for Muslims in this day and hereafter. The most important positive deeds according to Nursi is affirming faith in order to achieve the pleasure of Allah s.w.t., because the greatest symbol and the culmination of all the positive activities of mankind is serving for a faith. Thus, this study will reveal Nursi's concept in an effort to de-radicalization and counterterrorism as an issue of humanity until now. This study uses qualitative methods in analyzing the thoughts and ideas of Said Nursi in realizing the positive action and avoiding destructive action based on a review of literature on his work "Risale-i Nur". Some important results of this study state that the principle thought of Nursi is based on the values of al-Quran and al-Hadith who brought the message of peace and always avoid the negative actions. According to Nursi, edifying the education, strengthening positive values in social life by promoting love and affection and initiating the true jihad (al-jihad al-ma'nawi) are real solutions to save humanity from radicalism and terrorism.
\end{abstract}

Keywords : Positive Action, De-radicalization, Counter-terrorism, and al-Jihad al-Ma'nawi. 


\section{A. Pendahuluan}

Pemberitaan mengenai aksi-aksi kekerasan, tindak terorisme serta radikalisme di berbagai-bagai belahan dunia hingga akhir-akhir ini makin membuka kesadaran kolektif umat manusia, bahwa tindakan destruktif tersebut merupakan musuh yang harus dihadapi bersama. Tantangan menyelesaikannya tentu tidak akan efektif dan komprehensif jika ditanggulangi dengan upaya ofensif apalagi jika diselesaikan dengan tindak kekerasan yang sama atau serupa.

Oleh karena itu perlu dikedepankan upaya preventif yang lebih mempunyai efek dan kesan lebih berarti meski tentu saja akan memerlukan masa lebih panjang dalam pelaksanaannya. Dengan demikian upaya meredam radikalisasi dan melawan terorisme dengan menggunakan pendekatan ini perlu mengurai akar dari munculnya aksi-aksi kekerasan, radikalis dan teroris tersebut.

Karena itulah tulisan singkat ini akan menawarkan sekaligus menganalisa pokok-pokok pemikiran Bediuzzaman Said Nursi, sosok ulama kebangsaan Turki, dalam upaya deradikalisasi dan kontra terorisme melalui kajian terhadap karya masterpiece-nya "Risale-i Nur" yang mempunyai peran nyata pada masanya pada saatsaat genting peralihan kekuasaan dari sistem khilafah Uthmaniyyah kepada sistem pemerintahan Republik yang sekuler.

Adapun pondasi pemikiran Said Nursi dalam menghadapi terorisme dan radikalisme ini dilandasi oleh pemahaman dan penghayatan yang mendalam terhadap dua sumber rujukan utama dalam Islam, yakni al-quran dan al-hadits. Buah dari kontemplasi panjang Said Nursi ini menghasilkan konsep "Amal Positif" atau al-'amal al-ijabi (Positif Action) yang menjadi acuan dari setiap nilai-nilai penting yang menjadi senjata untuk melemahkan dan melumpuhkan aksi-aksi radikalisme dan terorisme yang digagas oleh Said Nursi.

\section{B. Biografi Ringkas Said Nursi}

Said Nursi (1877-1960 M) yang mendapat julukan Bediuzzaman ${ }^{1}$ dilahirkan di desa Nurs, wilayah Isparit, Anatolia bagian Timur, Turki. ${ }^{2}$ Anak keempat dari tujuh

${ }^{1}$ Bediuzzaman artinya keajaiban zaman. Menurut guru spiritualnya, syekh Fethullah Efendi, Nursi memiliki kesamaan dengan Bediuzzaman al-Hamadaniy (969-1007 M) seorang penyair terkenal pada masanya dalam kelebihan daya ingat dan daya fahamnya yang kuat. 
bersaudara ini lahir di tengah keluarga Kurdi dari pasangan Molla Mirza dan Nuriyah. Ayahnya biasa dipanggil dengan sufi Mirza merupakan generasi kedua utusan dakwah yang dikirim dari Cizre di wilayah Tigris untuk menyebarkan agama di kawasan itu, manakala ibunya Nuriye berasal daripada kampung Bilkan yang berjarak tiga jam dari kampung Nurs. ${ }^{3}$

Said Nursi kecil dikenal memiliki kecerdasan di atas rata-rata anak seusianya serta minatnya yang kuat dalam mendalami ilmu (baik agama maupun sains modern). Ia tumbuh menjadi tokoh yang diperhitungkan di Turki dan dunia Islam pada tahuntahun menjelang runtuhnya kekhalifahan Utsmaniyah dan masa peralihan Turki menjadi negara Republik. ${ }^{4}$

Sukran Vahide membagi kehidupan Said Nursi dalam tiga periode: pertama, periode Said Lama (Said al-Qadim) yang berlangsung selama masa kanak-kanak hingga usia mudanya yang ditandai dengan kehidupan mencari ilmu dan pengalaman berpolitik serta keterlibatannya dalam aktifitas sosial dan keummatan. Periode kedua, dinamakan dengan periode Said Baru (Said al-Jadid) yang dimulai setelah masa transformasi paradigma berpikirnya pada sekitar tahun 1920 atau 1921 M. Periode kedua ini ditandai dengan kebiasaannya meninggalkan kegaduhan sosial dan politik, meninggalkan filsafat dan bacaan-bacaan rasional lainnya yang ia rasakan menghalangi kemajuan ruhaninya. ${ }^{5}$

Adapun periode ketiga adalah periode Said Ketiga (Said al-Tsalits) yang berlangsung pada masa 10 tahun akhir hayatnya bermula dari tahun 1950 hingga tahun 1960 M. Sebagian masa tua Nursi ini ia habiskan untuk menyimak dan melakukan revisi atas salinan Risale-i Nur, mencetak dan menyebarkan karyanya ini sebanyak mungkin, melakukan lawatan kepada para murid dan simpatisan gerakan Nur di samping melakukan regenerasi kaum muda untuk melanjutkan misi dakwahnya ke depan. ${ }^{6}$

\footnotetext{
2 Said Nursi, Sirah Dzatiyah (Cairo: Syarikat Sozler, 2011), h. 57.

${ }^{3}$ Colin and Hasan, Said Nursi: Makers of Islamic Civilization (London: Oxford Centre for Islamic Studies, 2009), h. 5.

${ }^{4}$ Muhammad Faiz and Ibnor Azli, “Unsur Sufisme Dalam Konsep Pendidikan Said Nursi,” NIZHAM 4, no. 02 (Desember 2015): h. 185.

${ }^{5}$ Sukran Vahide, Biografi Intelektual Bediuzzaman Said Nursi (Jakarta: Anatolia Prenada, 2007), h. 199-200.

${ }^{6}$ Ibid., h. 343-344.
} 
Selama sekitar 25 tahun perjalanan hidupnya, Said Nursi menjalani kehidupan berat di tempat pengasingan dan penjara karena menentang kebijakan dan kampanye sekularisasi yang dilancarkan oleh pemerintahan Partai Rakyat Republik (Cumhuriyet Halk Partisi) yang dipimpin oleh Mustafa Kemal. ${ }^{7}$ Setidak-tidaknya Nursi mengalami tiga kali pembuangan ke tempat terpencil dan tiga kali dikurung dalam tahanan antara tahun 1927-1950 M. Namun dalam keadaan seperti inilah sebagian besar karyanya "Risale-i Nur" dapat ia tulis secara sembunyi-sembunyi dan disebarkan oleh muridmuridnya ke segala penjuru Turki dan beberapa kawasan Islam lainnya. ${ }^{8}$

Karakteristik utama yang dimiliki Risale-i Nur adalah menggunakan nalar dan hati untuk mengungkap kebenaran al-Quran, menjelaskan hakikat penciptaan alam semesta serta bertujuan menyelamatkan iman. Gerakan Nur yang diperjuangkan oleh Nursi bersama para muridnya ini berusaha untuk memperjuangkan iman dan menyebarkan al-Quran dengan cara yang damai melalui tindakan yang positif (al-'amal al-ijabi). ${ }^{9}$

Di antara perjuangan positif Nursi dalam memperbaiki kondisi Turki dan dunia Islam saat itu adalah konsistensinya dalam menulis "Risale-i Nur" sebagai sarana menyampaikan solusi atas problematika umat. Karya magnum opus-nya ini mengandung lebih dari 130 risalah dan terdiri dari lebih 6000 halaman yang ditulis dalam bahasa Turki dan 15 risalah lainnya ditulis dalam bahasa Arab. Risalah ini terdiri dari sembilan jilid buku yang bertajuk (1) al-Kalimat, (2) al-Maktubat, (3) al-Lama'at, (4) alSyua'at, (5) Isyarat al-I'jaz fi Madhan al-Ijaz (6) al-Matsnawi al-Arabi al-Nuri, (7) al-Malahiq, (8) Shayqal al-Islam dan terakhir jilid (9) Sirah Dzatiyah yang merupakan biografi kehidupan Said Nursi.

\section{Pengertian Radikalisme dan Terorisme}

Secara semantik, radikalisme adalah faham atau aliran yang menginginkan perubahan atau pembaharuan sosial dan politik dengan cara kekerasan atau secara drastis. Asal kata "radikalisme" diambil dari bahasa Inggris "radical" yang

\footnotetext{
${ }^{7}$ Mustafa Kemal (1881-1938 M) menjadi presiden pertama Turki pada 29 Oktober 1923. (lihat Abdul Latip Talib, Mustafa Kamal Ataturk Penegak Agenda Yahudi, (Selangor: PTS Litera Utama Sdn. Bhd, 2011).

${ }^{8}$ Muhammad Faiz, “Integrasi Nilai Spiritual, Intelektual Dan Moral Dalam Konsep Pendidikan Said Nursi," AR-RISALAH XI, no. 1 (April 2013): h. 22.

${ }^{9}$ Sukran Vahide, Biografi Intelektual Bediuzzaman Said Nursi, h. 22.
} 
mempunyai arti "sampai ke akar-akarnya". Sedangkan pendapat lain menyatakan radikalisme berasal dari kata "radix", yang juga berarti "akar". Dengan demikian orang-orang radikal adalah orang yang menginginkan perubahan terhadap situasi yang ada dengan melakukan tindakan sporadis sampai ke akar-akarnya. Adapun dalam Ensiklopedia Nasional Indonesia, radikalisme secara bahasa berarti aliran yang ekstrem, fundamental atau mengakar. ${ }^{10}$

Radikalisme dapat dipahami sebagai suatu sikap atau posisi yang mendambakan perubahan terhadap status quo dengan cara menghancurkannya secara total dan menggantinya dengan sesuatu yang baru sama sekali. Pada kebiasaannya tindakan yang dilakukan tersebut bersifat revolusioner secara drastis melalui jalan kekerasan (violence) dan perilaku yang ekstrem. ${ }^{11}$ Pendapat yang lain menambahkan ciri khas pemikiran radikal yang menjadi karakteristik kelompoknya antara lain seperti: sikap intoleran terhadap keyakinan dan pemahaman yang berbeda, sikap fanatik dengan merasa dirinya saja yang benar, sikap eksklusif dan enggan berdialog, serta tindakan revolusioner dalam mencapai tujuan meski dengan menggunakan kekerasan. ${ }^{12}$

Secara konseptual istilah radikalisme sebenarnya mengalami perkembangan makna. Menurut Farish A. Noor seperti dalam kajian Abdul Mukti menerangkan bahwa telah terjadi peralihan paradigma dan wacana yang menyebabkan bercampuraduknya antara konsep radikalisme dan "militan". Pengertian radikalisme menurut penuturan Abdul Mukti, pertama-tama harus diletakkan secara netralakademik sebagaimana definisi yang dilontarkan oleh Sartono Kartodirjo, yaitu sebagai "gerakan sosial yang menolak secara menyeluruh tertib sosial yang sedang berlaku yang ditandai dengan kejengkelan moral yang kuat untuk menentang dan bermusuhan dengan kaum yang punya hak-hak istimewa dan yang berkuasa". ${ }^{13}$

Karena pendefinisian pada umumnya merupakan sebuah konsep yang selalu menyertakan kemungkinan untuk berubah, maka konsep radikalisme pun demikian juga bisa berubah kepada makna positif dan negatif. ${ }^{14}$ Menurut kajian Emna Laisa,

\footnotetext{
${ }^{10}$ Abdul Mukti Ro' uf, "Mengurai Radikalisme Agama Di Indonesia Pasca Orde Baru," ULUMUNA XI, no. 1 (June 2007): h. 160-166.

${ }^{11}$ M. Amin Rais, Cakrawala Islam (Bandung: Mizan, 1999), h. 132.

12 Emna Laisa, “Islam Dan Radikalisme,” ISLAMUNA I, no. 1 (June 2014): h. 3.

${ }^{13}$ Abdul Mukti Ro' uf, “Mengurai Radikalisme Agama Di Indonesia Pasca Orde Baru,” h. 161.

${ }^{14}$ Ibid., h. 162.
} 
radikalisme tidaklah serta-merta menjadi sinonim dengan tindakan yang ekstrim dan selalu berujung kekerasan. Sebab ia dapat bermakna positif jika dijalankan dengan pemahaman agama yang komprehensif dan diamalkan dalam ranah privat. ${ }^{15}$ Adapun dalam makalah ini pengertian radikalisme yang dimaksud adalah paham yang melandaskan aksi pada kekerasan dan pemaksaan dalam ranah (antar) agama maupun dalam nuansa keberagamaan yang bersifat negatif dan destruktif.

Sedangkan terorisme secara umum dipahami sebagai tindakan yang menimbulkan teror (ketakutan). Dalam bahasa Arab disebut dengan istilah alirhabiyyah. Secara etimologi kata al-irhab adalah berasal dari kata kerja arhaba-yurhibu yang mempunyai akar kata rahiba, yang mempunyai arti melakukan intimidasi atau ancaman. ${ }^{16}$ Sinonim dengan akar kata ini adalah akhafa (menciptakan ketakutan), dan $f a z z a^{\prime} a$ (membuat kengerian/kegetaran). Manakala dari segi terminologi pengertian alirhab adalah rasa takut yang ditimbulkan akibat aksi-aksi kekerasan, seperti pembunuhan, pengeboman dan perusakan. Adapun pengertian al-irhabi (terrorist) adalah orang yang menempuh jalan teror dan kekerasan tersebut. ${ }^{17}$

Menurut laporan Imam Mustofa, sebagaimana dalam kajian Loudewijk F. Paulus terorisme dapat lahir karena dilatarbelakangi oleh berbagai motif dan sebab. Di antara motif utama yang mendorong munculnya terorisme adalah alasan rasional, psikologi dan budaya. Adapun sebab-sebab lainnya hanyalah merupakan perluasan dan penjabaran dari ketiga motif utama tersebut. Termasuk aksi-aksi terorisme yang terjadi karena alasan dan motivasi agama seperti diungkapkan dalam kajian Whittaker. Munculnya sentimen agama tentu juga dapat memicu tumbuhnya radikalisme dan tindakan terorisme. ${ }^{18}$

\section{Urgensi Deradikalisasi dan Kontra Terorisme}

Deradikalisasi adalah satu upaya dalam menanggulangi penyesatan faham agama yang mengedepankan tindakan irrasional, rigid, menindas dan sering menggunakan kekerasan, yang mana semestinya agama menampakkan wajahnya

\footnotetext{
${ }^{15}$ Emna Laisa, “Islam Dan Radikalisme,” h. 2.

${ }^{16}$ Ahmad Warson Munawwir, Kamus Al-Munawwir (Surabaya: Pustaka Progressif, 1997), h. 539.

${ }^{17}$ Kasjim Salenda, "Terorisme Dalam Perspektif Hukum Islam," ULUMUNA XIII, no. 1 (June 2009): h. 83-84.

${ }^{18}$ Imam Mustofa, “Deradikalisasi Ajaran Agama: Urgensi, Problem Dan Solusinya,” AKADEMIKA 16, no. 2 (Desember 2011): h. 7.
} 
yang penuh dengan nilai-nilai toleransi (tasamuh), moderat (tawassuth/wasathiy), lurus dalam bingkai keadilan (I'tidal) dan menjadi rahmat bagi alam (rahmah li al-'alamin).

Sepertimana laporan Mustofa dalam kajian Jeffrie Geovanie "deradikalisasi agama merupakan upaya untuk menanamkan pemahaman agama yang ramah dan damai dalam perspektif kebhinekaan sehingga setiap pemeluk agama mau menerima perbedaan dengan wajar (tulus) dan lapang dada. Karena merespon perbedaan secara radikal, tanpa kompromi bertentangan dengan ajaran kedamaian agama" ${ }^{19}$

Deradikaliasi yang berkesan (impresif) tentu membutuhkan waktu yang tidak sebentar, karena ia juga mencakup proses deideologisasi atas pemahaman yang telah terbangun sebelumnya. Oleh demikian deradikalisasi harus dilakukan dengan menggunakan pelbagai pendekatan yang positif baik dari segi psikologi, keagamaan, sosial-budaya, ekonomi, hukum dan kekuasaan (politik) dalam tempoh yang panjang.

Adapun kontra terorisme merupakan upaya untuk menanggulangi gangguan teror yang dilancarkan oleh para terrorist yang menginginkan ketidakstabilan kondisi masyarakat, memecah integrasi sosial dan pemaksaan agenda kelompoknya yang sering kali menggunakan tindak kekerasan dalam aksinya. Terorisme ini dapat lahir dari benih puritanisme yang kemudian berubah ke arah radikalisme dan ekstrimisme. ${ }^{20}$

Dengan demikian masih maraknya aksi-aksi radikalisme dan terorisme hingga saat ini semakin menguatkan urgensi upaya deradikalisasi dan kontra terorisme dengan mendorong semua pihak untuk terus berpartisipasi aktif meredam cara-cara kekerasan dalam kapasitas masing-masing sebagai warga negara yang mencintai keutuhan bangsa dan negaranya.

Upaya deradikalisasi dan kontra terorisme dengan pendekatan agama misalnya akan menemui beberapa tantangannya tersendiri, sebab orang-orang yang sudah terkena doktrin radikal akan sangat tergantung respon dan penerimaannya terhadap program deradikalisasi ini kepada latar belakang pemahaman agama yang dimiliki sebelumnya.

Indoktrinasi faham radikal kepada orang-orang yang awam dan minim pemahaman agamanya tentu akan lebih mudah dibandingkan dengan transformasi

\footnotetext{
${ }^{19}$ Ibid., h. 4.

${ }^{20}$ Emna Laisa, “Islam Dan Radikalisme,” h. 15.
} 
ajaran radikal kepada orang-orang yang telah luas wawasan dan dialektika keagamaannya. Bahkan kecenderungan terinfeksi virus radikal akan sangat kecil jika seseorang secara basic berpikiran terbuka dan mau membaca berbagai sumber literatur yang berbeda.

Tantangan selanjutnya terletak pada konsep deradikalisasi dan kontra terorisme yang sesuai sehingga mempunyai impak positif dalam mengurangkan aksi dan tindak kekerasan yang mengorbankan kemanusiaan sehingga dewasa ini. Oleh itulah tulisan singkat ini akan mengupas konsep Said Nursi dalam upaya memerangi radikalisme dan terorisme dengan "Aksi positif" (Positive Action) sebagai jargonnya. Solusi yang ditawarkan Nursi ini merupakan intisari dari magnum opus-nya Risale-i Nur yang meliputi pembenahan dalam bidang pendidikan, mengedepankan rasa cinta dan kasih sayang sesama insan serta menggelorakan Jihad Ma'nawi sebagai alternatif dari pemaknaan jihad yang banyak diterapkan dan disalahartikan oleh kaum radikal dan para pemuja teror.

\section{E. Aksi Positif Sebagai Solusi Mengatasi Radikalisme dan Terorisme}

Aksi positif (al-'amal al-ijabi) dengan menghindari aksi destruktif dan negatif (al'amal al-takhribi wa al-salbi) merupakan prinsip dasar dari konsep yang digagas oleh Said Nursi sebagai upaya mengatasi laju radikalisme dan terorisme. Menurut kajian Ala'uddin Basyar ${ }^{21}$ sikap positif merupakan kaidah dasar yang melandasi karya masterpiece Nursi yakni Risale-i Nur yang telah menyumbangkan peranan berarti dalam keikutsertaannya menjaga stabilitas negara Turki pada saat menjelang runtuhnya Khilafah Utsmaniyah dan masa transisi periode kekuasaan kepada pemerintahan Republik Turki.

Menurut Ala'uddin sikap positif yang dikampanyekan Said Nursi dilandasi oleh beberapa nilai utama, yaitu antara lain harus dilandasi oleh ilmu (al-ilm), pengetahuan (al-ma'rifah), dakwah (al-tabligh), sifat qana'ah (al-iqna'), cinta (al-wudd) dan rasa kasih sayang (al-shafaqah) antar sesama. ${ }^{22}$ Nilai-nilai inilah yang telah membangun pribadi

\footnotetext{
${ }^{21}$ Prof. Dr. Ala'uddin Basyar lahir di Turki pada tahun 1947, beliau menulis buku yang berjudul "al-Kalimat min al-Nur" yang menghimpun istilah-istilah baru yang digagas oleh Said Nursi di dalam karyanya Risale-i Nur.

${ }^{22}$ Ala'uddin Basyar, “Al-Amal Al-Ijabi Al-Qa'idah Al-Tsabitah Li Umrin Madid,” AL-NUR 6 (July 2012): h. 127.
} 
Nursi menjadi sosok pelopor perdamaian dan pergerakan Islam yang positif di Turki ketika berhadapan dengan tuntutan disintegrasi bangsa oleh kelompok separatis Kurdi dan ancaman tindakan anarkisme kelompok radikal lain yang mengancam keamanan negara serta serangan kolonial yang ingin meruntuhkan kuasa Turki Utsmani.

Menurut Said Nursi untuk menjaga stabilitas kehidupan sosial dan menghindari perpecahan dan berlakunya kekacauan dalam masyarakat diperlukan lima prinsip utama yang harus menjadi kesepakatan dan kesadaran bersama, yaitu: adanya sikap saling menghormati (al-ihtiram al-mutabadil) antar warga, sifat kasih sayang antar sesama (al-syafaqah wa al-rahmah), menjauhi larangan dan pelanggaran-pelanggaran hukum (al-ibti'ad an al-haram), menjaga keamanan bersama (al-hifadz ala al-amn) serta mendahulukan ketaatan pada aturan yang telah disepakati (nabdzu al-faudha wa alghaughaiyyah wa al-dukhul fi al-tha'at). ${ }^{23}$

Landasan yang menjadi pijakan pandangan dan pemikiran positif Said Nursi di atas adalah penghayatan yang mendalam terhadap ayat al-Quran, surat al-Isra' ayat 15:

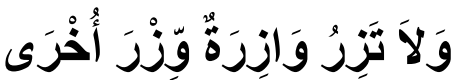

"Dan seseorang yang berdosa tidak dapat memikul dosa orang lain"

Menurut Nursi ayat tersebut menerangkan bahwa tidaklah boleh memberikan hukuman kepada seseorang akibat dosa dan kesalahan yang dilakukan oleh orang lain. ${ }^{24}$ Pemahaman ini sekaligus meruntuhkan ideologi radikal yang bersifat destruktif (al-takhribi) yang dipahami sebagian kelompok yang mengatasnamakan agama yang sering melancarkan aksi teror karena tidak puas dengan tatanan dunia yang tidak adil, namun dengan melakukan tindakan perusakan yang kontra-produktif sehingga memperpanjang siklus kerusakan itu sendiri.

Sebagai respon atas aksi radikalisme dan terorisme yang merusak tatanan sosial dan menyudutkan instansi agama, Said Nursi menawarkan beberapa solusi untuk mengatasi permasalahan ini sebagaimana ia tulis dalam jilid-jilid karyanya Risale-i Nur. Sebagai solusi utama Nursi mengusulkan perbaikan dan pembenahan dunia pendidikan secara konseptual, kedua ia mengampanyekan jalan cinta dan kasih

\footnotetext{
${ }^{23}$ Said Nursi, Sirah Dzatiyah, h. 443-444.

${ }^{24}$ Said Nursi, Al-Malahiq (Cairo: Syarikat Sozler, 2011), h. 400.
} 
sayang sebagai asas perjuangan, ketiga ia menggelorakan jihad maknawi atau perjuangan moral sebagai upaya deradikalisasi dan kontra terhadap terorisme.

\section{1) Pembenahan Institusi Pendidikan}

Dunia pendidikan menurut Said Nursi memerlukan pembenahan konseptual yang mendasar agar berdampak positif dalam melahirkan generasi yang moderat dan mempunyai sisi kemanusiaan yang kuat. Konsep pendidikan yang tepat menurut Nursi adalah integrasi dari tiga unsur utama pembentuknya, yakni memadukan ilmuilmu keagamaan (al-'ulum al-diniyah) dengan ilmu pengetahuan semesta modern (al'ulum al-kauniyyah al-haditsah) serta nilai-nilai moral yang diserap dari pengajaran sufistik. $^{25}$

Menurut Nursi ilmu agama merupakan cahaya penerang kalbu sedangkan ilmu sains modern adalah sinar yang menerangi akal di mana keduanya dapat menyelamatkan dari pelbagai syuhbat pemikiran dan ketertipuan nalar. ${ }^{26}$ Oleh karena itu perpaduan kedua-duanya akan melahirkan hakikat (kebenaran), adapun sebaliknya memisahkan keduanya hanya akan menimbulkan fanatisme sempit dan kecelaruan intelektual. ${ }^{27}$ Sebagaimana juga metafora lainnya yang digunakan oleh Nursi untuk menggambarkan pentingnya keilmuan dasar agama dan keilmuan sains (kosmik) modern sebagai dua pasang sayap burung yang tak mungkin terpisahkan.

Paradigma Nursi ini tentu berbeda sebagaimana dilontarkan oleh sebagian ilmuwan (scientist) kontemporer yang masih berfikiran distortif dan menganggap hakikat ilmu agama tidak mempunyai korelasi kebenaran dengan sains modern. Nursi secara terang-terangan membantah cara pandang seperti itu, sebab dalam konsep Nursi ilmu sains kekinian merupakan sarana untuk mengabdi (khidmah) kepada keimanan, ia mengungkap kedalaman pengetahuan yang belum terungkap di dalam al-Qur'an serta dapat menjelaskan hakikat agama Islam. ${ }^{28}$ Dalam keyakinan Nursi,

${ }^{25}$ Said Nursi, Shayqal Al-Islam (Cairo: Syarikat Sozler, 2011), h. 190.

${ }^{26}$ Said Nursi, Sirah Dzatiyah, h. 568-572.

${ }^{27}$ Ibid., h. 402.

${ }^{28}$ Azad Said, Said Nursi: Harakatuhu Wa Masyru'uhu Al-Ishlahiy Fi Turkiya (Damaskus: Dar alZaman, 2008), h. 324. 
Islam merupakan tuan dan pembimbing bagi segala ilmu, Islam menurutnya adalah sumber dan rahim bagi lahirnya segala keilmuan. ${ }^{29}$

Dalam konsep pendidikan Nursi metode (manhaj) dan asas pembelajaran yang digunakan adalah kajian terhadap topik-topik utama yang bersumber dari pengajaran al-Quran dan al-Hadits serta pandangan-pandangan ilmiah para ulama yang sebagiannya telah ia tulis di dalam karyanya Risale-i $N u r .{ }^{30}$ Risalah ini secara umum merupakan tafsir maknawi terhadap ayat-ayat al-Quran dengan visi utama menyelamatkan keimanan (inqadz al-iman) dan mengungkapkan kebenaran al-Quran.

Risalah Nursi ini merupakan ruh atas konsep pendidikan yang digagasnya yang memiliki cita-cita melahirkan generasi ulama yang mendalam ilmu agamanya dan sekaligus menguasai sains dan teknologi modern sebagai media mencapai kesadaran sepenuhnya atas hakikat penciptaan diri manusia (maqam al-ubudiyyah) namun dengan tetap mengedepankan nilai-nilai moral (akhlak mulia) baik kepada Tuhan, sesama manusia, maupun terhadap alam semesta. ${ }^{31}$

Karena itu Said Nursi pernah menggagas satu konsep pendidikan yang diyakininya dapat menjadi solusi mendasar atas segala permasalahan yang dialami bangsa Turki dan dunia Islam secara umumnya. Dia meyakini bahwa perbaikan satu generasi memerlukan perjuangan panjang dan harus dilakukan dengan bertahap dan dengan cara yang positif. ${ }^{32}$

Atas dorongan itulah pada tahun 1907 M Said Nursi pergi ke Istanbul untuk menyampaikan gagasannya kepada penguasa Khilafah Utsmaniyah ketika itu, Sultan Abdul Hamid II, terkait perbaikan dunia pendidikan yang dilihatnya dapat menjadi solusi atas keterpurukan bangsa Turki. Saat itu Nursi memelopori berdirinya lembaga pendidikan yang ia namakan "Madrasah al-Zahra" ${ }^{33}$ sebagai model pendidikan yang

\footnotetext{
${ }^{29}$ Said Nursi, Shayqal Al-Islam (Cairo: Syarikat Sozler, 2011), h. 21.

${ }^{30}$ Muhammad Faiz and Ibnor Azli, “Unsur Sufisme Dalam Konsep Pendidikan Said Nursi,” h. 190.

${ }^{31}$ Muhammad Faiz, “Integrasi Nilai Spiritual, Intelektual Dan Moral Dalam Konsep Pendidikan Said Nursi," h. 24-25.

${ }^{32}$ Sukran Vahide, Biografi Intelektual Bediuzzaman Said Nursi, h. 24-36.

33 Nama "Madrasah al-Zahra" terinspirasi dari nama Universitas al-Azhar di Mesir yang merupakan universitas Islam tertua yang menjadi kiblat ilmu di seantero dunia Islam. Namun karena letaknya di belahan benua Afrika, maka menurut Said Nursi perlu didirikan universitas serupa di belahan benua Asia. Oleh itu dipilih wilayah Turki bagian timur sebagai basis keilmuan yang memadukan ilmu
} 
memadukan tiga sistem pendidikan yang telah ada saat itu, yaitu sistem medrese sebagai pusat pengajaran ilmu-ilmu agama, mekteb atau sekolah umum konvensional sebagai tempat pengajaran ilmu sains modern dan teknologi serta tekke ${ }^{34}$ (zawiyah) tasawuf yang merupakan pusat kegiatan tarekat sufi yang banyak tersebar di seantero negeri. ${ }^{35}$

Wujudnya lembaga keilmuan yang komprehensif dan holistik sebagaimana digagas oleh Said Nursi di atas diharapkan dapat melahirkan generasi yang lebih berintegritas, bermoral mulia, cinta kemanusiaan, mempunyai pemahaman keagamaan yang mengakar (radical) dalam artian sesungguhnya yang berdimensi positif tentunya (memahami agama secara mendalam), berpikiran inklusif, mengedepankan persaudaraan sesama insan serta jauh dari sifat teror dan anarkis.

\section{2) Memilih Jalan Cinta dan Kasih Sayang}

Ajakan kepada jalan cinta (al-mahabbah) merupakan salah satu dari enam poin utama dari isi pidato keumatan dan kebangsaan yang pernah disampaikan Said Nursi di Damaskus, Suriah pada tahun 1911 M di Masjid Jami’ Bani Umayyah yang dihadiri oleh ribuan umat Islam dengan ratusan di antaranya adalah para ulama dan kaum cendekiawan dari penjuru negeri Syam. ${ }^{36}$ Dalam pengamatan Nursi umat Islam era modern kini sedang meradang karena menderita enam penyakit akut yang sedang menyerangnya, yaitu hidup dalam keputusasaan (hayat al-ya's), hilangnya kejujuran dalam kehidupan sosial dan politik, cinta permusuhan (hubb al-'adawah), kebodohan (aljahl), despotisme (al-istibdad $)^{37}$ dan egoisme. ${ }^{38}$

syariah (diniyah) dan ilmu modern (haditsah) karena letaknya yang strategis di antara wilayah India, negara-negara Arab, Iran, Kaukasia dan Turkistan.

${ }^{34}$ Tekke merupakan bahasa Turki yang diadopsi dari bahasa Arab "takiyyah" (bentuk pluralnya takaya) yang mempunyai arti sinonim dengan "zawiyah" (plural: zawaya) yakni serupa pondok pesantren sebagai pusat belajar komunitas sufi yang terdiri dari bangunan masjid (mushala) dan kompleks perumahan santri beserta guru atau mursyid tasawuf yang tersebar di berbagai kawasan di Turki pada masa kekuasaan Utsmaniyah (lihat Abdul Fatah, al-Ulama al-Uzzab alladzina Atsaru al-Ilm ala al-Zawaj, (Beirut: Dar al-Basya'ir al-Islamiyyah, 1999), h. 239).

${ }^{35}$ Muhammad Faiz and Ibnor Azli, “Unsur Sufisme Dalam Konsep Pendidikan Said Nursi," h. 187-188.

${ }^{36}$ Pidato Said Nursi ini dikenal dengan "Khutbah Syamiyah" (Damascus Sermon) yang berisi penjelasan mengenai enam penyakit ruhani yang tengah diderita oleh umat manusia pada umumnya dan umat Islam pada khususnya. Sekaligus Nursi menawarkan enam solusi sebagai penawar keenam penyakit itu.

${ }^{37}$ Despotisme adalah penindasan, perlakuan kepada orang lain secara semena-mena. Yakni pemaksaan yang dipayungi kekuasaan yang bersumber dari pendapat satu orang. Despotisme merupakan 
Menurut pandangan Said Nursi dalam kehidupan ini tidak ada yang lebih layak untuk dicintai kecuali cinta itu sendiri dan tidak ada yang lebih patut dibenci dan dimusuhi kecuali rasa kebencian dan permusuhan itu sendiri. ${ }^{39}$ Sifat cinta dan rasa kasih sayang merupakan rumah besar bagi kemanusiaan yang ironisnya semakin rapuh di era kemajuan zaman akhir-akhir ini. Maraknya aksi anarkisme, radikalisme dan tindak terorisme hingga saat ini merupakan indikasi semakin parahnya penyakit manusia yang berupa sifat permusuhan (hubb al-'adawah) yang pada dasarnya bertentangan dengan fitrah penciptaannya.

Dalam merawat rasa cinta kepada sesama, Said Nursi memberikan landasan dalil dari hadits Nabi s.a.w. yang memberikan peringatan kepada muslim yang sedang berselisih dengan saudara muslim lainnya agar tidak saling berdiam diri tanpa tegur sapa lebih dari tiga hari. Sebaliknya hendaklah satu di antara keduanya terlebih dahulu menyapa dan menyampaikan salam (pesan perdamaian) sehingga dialah yang dinilai sebagai orang yang paling baik di antara keduanya. ${ }^{40}$

Menurut Nursi sifat permusuhan sesama manusia merupakan bentuk kezaliman baik dilihat dari segi hakikat maupun hikmahnya. Ia lantas juga memberikan contoh beberapa paradigma yang tidak tepat yang dipahami oleh sebagian kalangan sehingga dapat memicu rasa permusuhan. Misalnya pandangan sebagian orang yang mengatakan "sungguh hanya pendapatku lah yang paling tepat, bukan pendapat yang lain". Pandangan ini merupakan cermin kesempitan berpikir seseorang yang meyakini bahwa hanya dirinya yang paling benar dan selamat sedang yang lain adalah salah dan sesat.

Sebaliknya menurut Nursi paradigma seperti itu semestinya dirubah kepada pandangan yang lebih positif, sehingga pernyataan yang tepat adalah "sungguh pendapatku ini adalah benar dan lebih baik". Dengan demikian kalimat seperti ini hanya akan menegaskan kebenaran pendapatnya pribadi tanpa menafikan

\footnotetext{
landasan bagi tirani yang menjadi lahan subur terjadinya eksploitasi yang menafikan kemanusiaan (Lihat Sukran Vahide, Biografi Intelektual.., h. 98).

${ }^{38}$ Said Nursi, Sirah Dzatiyah, h. 142.

${ }^{39}$ Said Nursi, Shayqal Al-Islam, 2011, h. 478.

${ }^{40}$ Hadits ini diriwayatkan oleh al-Bukhari dalam bab al-Adab dan bab al-Isti'dzan serta diriwayat oleh Muslim di dalam bab al-Birr.
} 
kemungkinan kebenaran pendapat orang lain. ${ }^{41}$ Cara berpikir yang inklusif dan membuka diri atas pendapat dan pandangan orang lain inilah yang akan menjauhkan seseorang dari merasa paling benar sendiri sehingga menyelamatkan diri dari fundamentalisme sempit yang hanya akan melahirkan radikalisme dan akhirnya berujung dengan aksi-aksi terorisme.

\section{3) Menggelorakan Jihad Maknawi}

Adapun solusi terakhir yang disuarakan Said Nursi untuk mengatasi maraknya aksi radikalisme dan terorisme adalah dengan memperjuangkan jihad maknawi (aljihad al-ma'nawi) atau jihad moral dan spiritual (ruhaniyah). Bentuk perjuangannya di sini adalah melalui tindakan positif dan langkah damai dengan menjaga stabilitas keamanan dalam negeri ( $\mathrm{ta}^{\prime} \mathrm{min}$ al-amn al-dakhili) dan mencegah terjadinya tindakan anarkis yang merusak, utamanya kerusakan yang berupa non-fisik (al-takhribat alma'nawiyah). ${ }^{42}$

Manakala perjuangan untuk membela Islam namun dilakukan dengan metode secara langsung, keras dan melalui jalur politik (busuk) menurut Nursi adalah perjuangan yang bercorak materi (al-jihad al-maddi) dan dalam penilaiannya tidak akan menyelesaikan masalah secara mendasar. ${ }^{43}$ Malahan sebaliknya dikhawatirkan akan dapat memberikan citra yang buruk terhadap wajah asli Islam yang teduh dan penuh kasih sayang.

Perjuangan positif yang ideal bagi Nursi sebagaimana yang telah ditunjukkan oleh gerakan Risale-i Nur yang dirintisnya adalah perjuangan yang didasari oleh rasa kasih sayang antar sesama (al-syafaqah), rasa keadilan (al-adl) merata, kebenaran (al-haq), hakikat (al-haqiqah) dan perasaan sepenanggungan untuk menempuh jalur perjuangan non-politis atau terlibat dalam perebutan kekuasaan secara praktis. ${ }^{44}$

Perjuangan moral sejatinya menurut Nursi adalah perjuangan melawan tindakan destruktif yang bersifat non-materi (maknawi), karena itu solusinya juga perlu dilakukan melalui tindakan positif yang bersifat maknawi atau non-materi. Adapun puncak dari perjuangan maknawi ini menurutnya adalah perkhidmatan dalam

\footnotetext{
${ }^{41}$ Said Nursi, Al-Maktubat (Cairo: Syarikat Sozler, 2011), h. 325-327.

${ }^{42}$ Said Nursi, Al-Malahiq, h. 400.

${ }^{43}$ Sukran Vahide, Biografi Intelektual Bediuzzaman Said Nursi, h. 365.

${ }^{44}$ Said Nursi, Sirah Dzatiyah, h. 443.
} 
mengokohkan iman umat Islam dari kekufuran mutlak (atesime), bahkan khidmat keimanan ini ia nilai sebagai simbol teragung dari tindakan positif yang mungkin dilakukan seseorang. ${ }^{45}$ Sebab ideologi ateis ini menurut Nursi adalah di antara pemicu utama berlakunya tindakan anarkis dan teroris (al-faudha wa al-irhab). ${ }^{46}$

Gagasan jihad maknawi ini pada dasarnya merupakan transformasi pemaknaan jihad sebenarnya yang pada praktiknya banyak disalahgunakan dan dimanfaatkan oleh kalangan radikalis dan teroris. Mereka dalam aksi-aksinya tidak jarang memberikan doktrin "jihad suci" sebagai pembenaran atas tindak terorisme yang mereka lancarkan, baik untuk menarik minat dalam proses rekruitmen anggota baru maupun dalam eksekusi tindakan mereka sendiri.

Pemaknaan term "jihad" secara salah oleh sebagian kecil kalangan ini merupakan permasalahan internal umat Islam sendiri sehingga membentuk citra dan kesan negatif, baik terhadap istilah jihad (sebagai ajaran yang memang ada dalam Islam) maupun terhadap masyarakat muslim di seluruh penjuru dunia yang ikut merasakan efek negatifnya. Sehingga tidak dapat dihindarkan adanya pemaknaan jihad yang identik dengan terorisme yang sering kali dikaitkan dengan umat Islam yang berasal dari pandangan para Sarjana Barat. ${ }^{47}$

Karena itulah Said Nursi mengalihkan perjuangan fisik umat dalam membela agama Islam kepada arah perjuangan secara non-materi (moral-spiritual), yakni dengan jihad kata-kata (al-jihad al-ma'nawi) dengan jalan mengukuhkan iman di dalam hati dan mengamalkan tindakan positif dalam kehidupan bermasyarakat demi tercapainya harmoni kehidupan manusia yang diliputi oleh kebahagiaan hakiki nan penuh kedamaian. ${ }^{48}$

\section{F. Simpulan}

Tindak radikalisme dan terorisme yang masih belum hilang dari pemberitaan nasional maupun dunia internasional hingga detik ini menyisakan pekerjaan rumah yang berat bagi kemanusiaan yang harus tanpa henti mengampanyekan perlawanan

\footnotetext{
${ }^{45}$ Ala'uddin Basyar, “Al-Amal Al-Ijabi Al-Qa'idah Al-Tsabitah Li Umrin Madid,” h. 129.

${ }^{46}$ Said Nursi, Al-Malahiq, h. 403.

${ }^{47}$ Lukman Arake, “Pendekatan Hukum Islam Terhadap Jihad Dan Terorisme," ULUMUNA 16, no. 1 (June 2012): h. 190.

${ }^{48}$ Sukran Vahide, Biografi Intelektual Bediuzzaman Said Nursi, h. 346.
} 
terhadap aksi kekerasan dan destruktif namun di waktu bersamaan dituntut untuk menyikapinya dengan cara yang positif dan konstruktif. Sebab jika aksi teror dan kekerasan dilawan dengan aksi yang serupa, maka hanya akan memperpanjang siklus teror dan tindak kekerasan itu terus berulang. Oleh itu konsep yang ditawarkan oleh Said Nursi dalam menanggulangi aksi radikalisme dan terorisme ini perlu diterapkan pada masa kini.

Dengan menggagas slogan "Aksi Positif" (al-'amal al-ijabi), Said Nursi berusaha meredam potensi tindak anarkis dan teroris, sekaligus mengatasi tindakan tersebut supaya tidak meluas bahkan bisa ditekan agar tidak kembali terjadi di kemudian hari. Di antara konsep Nursi dalam melawan anarkisme dan terorisme adalah dengan membenahi sistem pendidikan secara mendasar, menguatkan nilai-nilai positif dalam kehidupan masyarakat (utamanya persatuan, kasih sayang dan rasa sepenanggungan) serta dengan menggelorakan jihad moral atau ia sebut dengan Jihad Maknawi (al-jihad al-ma'nawi). Melalui karyanya "Risale-i Nur" yang berjumlah sembilan jilid ini dan terdiri lebih dari 6000 halaman ia dedikasikan sepenuhnya untuk kedamaian umat manusia, sebagai lentera penerang kalbu serta petunjuk kebahagiaan umat yang merupakan tafsir maknawi al-Quran yang memancarkan nilai-nilai humanis dan rahmat bagi sekalian alam.

\section{DAFTAR PUSTAKA}

Abdul Mukti Ro'uf. "Mengurai Radikalisme Agama Di Indonesia Pasca Orde Baru." ULUMUNA XI, no. 1 (June 2007).

Ahmad Warson Munawwir. Kamus Al-Munawwir. Surabaya: Pustaka Progressif, 1997.

Ala'uddin Basyar. "Al-Amal Al-Ijabi Al-Qa'idah Al-Tsabitah Li Umrin Madid." ALNUR 6 (July 2012).

Azad Said. Said Nursi: Harakatuhu Wa Masyru'uhu Al-Ishlahiy Fi Turkiya. Damaskus: Dar al-Zaman, 2008.

Colin, and Hasan. Said Nursi: Makers of Islamic Civilization. London: Oxford Centre for Islamic Studies, 2009.

Emna Laisa. “Islam Dan Radikalisme.” ISLAMUNA I, no. 1 (June 2014). 
Imam Mustofa. "Deradikalisasi Ajaran Agama: Urgensi, Problem Dan Solusinya." AKADEMIKA 16, no. 2 (Desember 2011).

Kasjim Salenda. “Terorisme Dalam Perspektif Hukum Islam.” ULUMUNA XIII, no. 1 (June 2009).

Lukman Arake. "Pendekatan Hukum Islam Terhadap Jihad Dan Terorisme." ULUMUNA 16, no. 1 (June 2012).

M. Amin Rais. Cakrawala Islam. Bandung: Mizan, 1999.

Muhammad Faiz. “Integrasi Nilai Spiritual, Intelektual Dan Moral Dalam Konsep Pendidikan Said Nursi." AR-RISALAH XI, no. 1 (April 2013).

Muhammad Faiz, and Ibnor Azli. "Unsur Sufisme Dalam Konsep Pendidikan Said Nursi." NIZHAM 4, no. 02 (Desember 2015).

Said Nursi. Al-Maktubat. Cairo: Syarikat Sozler, 2011.

- - - . Al-Malahiq. Cairo: Syarikat Sozler, 2011.

- - - Shayqal Al-Islam. Cairo: Syarikat Sozler, 2011.

- - - Shayqal Al-Islam. Cairo: Syarikat Sozler, 2011.

- - - Sirah Dzatiyah. Cairo: Syarikat Sozler, 2011.

Sukran Vahide. Biografi Intelektual Bediuzzaman Said Nursi. Jakarta: Anatolia Prenada, 2007. 